\title{
Technique efficiency and financial crises in China: Empirical study based on SFA of panel data
}

\author{
$\underline{\text { Jia R. }}^{1}$, D. Zhao ${ }^{1}$, X. Guo ${ }^{2}$ and D. Marinova ${ }^{2}$

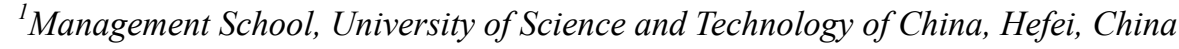 \\ ${ }^{2}$ Curtin University Sustainability Policy (CUSP) Institute, Curtin University, Western Australia \\ Email: ryjia@email.ustc.edu.cn
}

\begin{abstract}
China's recent remarkable economic development has also witnessed changes in technique efficiencies associated with factors, such as R\&D investment, institutional factors, human capital accumulation and trade openness. Based on stochastic frontier analysis (SFA) panel data, this paper evaluates these changing technique efficiencies in 30 Chinese administrative regions over the period from 1996 to 2009. It also conducts a quantitative evaluation of the influence administrative expenditures have on technique efficiencies and analyses the impacts of financial crises on the technique efficiencies of the Chinese provinces.

The results from this study show that China's economy is typically investment-driven and is at a stage of increasing scale of development when governmental expenditures on education, health, public goods and R\&D can improve the provincial technique efficiencies. This study also points out serious imbalance in China's technique efficiencies with those in the eastern regions being much higher than for the central and western regions.

Furthermore financial crises have impacts on the technique efficiencies, including the shockwaves sent by the Asian financial crisis in 1997 and the 2008 Global Financial Crisis. The technique efficiencies have been further influenced significantly by the recent global financial crisis whose impact has been felt over a longer period of time.

Optimising the structure of the government expenditure, improving its efficiencies and facilitating the development of the central and western regions are major tasks for increasing the provincial technique efficiencies in China.
\end{abstract}

Keywords: Evaluation model, Fiscal policy, Stochastic frontier analysis, Influencing factors 


\section{INTRODUCTION}

Since 1978, China achieved remarkable economic development and in the last decade its annual GDP growth rate was over 9\%. Many economists, e.g. Lau and Brada (1990), Wu (1995), Yuan et al. (2005), Fu and Wu (2006), Wang et al. (2006), Fan and Wang (2009), to name a few among others, have analysed China's changing technique efficiency for possible causes for its economic growth, such as R\&D investment, institutional factors, human capital accumulation and trade openness. This study builds on this valuable research.

In the endogenous economic growth model, financial expenditure is an important factor influencing economic growth. First, government expenditure on education and public health can influence labor productivity and effective labor supply (e.g. Uzawa, 1965; Lucas, 1988). Increase in the educational level of the labour force can lead to a long-term output growth. Expenditure on public health can increase the effective labour supply, and can also improve the ability of labour to receive education and new technology. Government expenditure can also influence capital productivity and effective capital supply, which can be seen in the following areas: government expenditure on public goods can permanently improve the productivity of private capital, therefore it can be positively influential on the long-term growth rate of output; social and political stability can influence resource configuration efficiency, therefore government expenditure on defence and public order can influence capital productivity; research and development funded by the government can improve the capital output rate. Investing in R\&D positively influences GNP (Lichtenberg, 1992). However, no research has been conducted on the influence of financial expenditure on China's technique efficiency. Using the four perspectives of education and health, defence and safety, public goods and R\&D, this study conducts empirical analysis on the influence of China's financial expenditure on technique efficiency. Furthermore, financial expenditures, as the government's macro-control leverage, are influenced by the external economic environment. The study also explores the impacts of the 1997 Asian financial crisis and the 2008 global financial crisis on China's technique efficiencies.

This paper introduces a model, explains the data sources and the selection process for the relevant indexes. It then explores the technique efficiencies of China's provinces and the factors influencing them. The impact of the financial crises is also examined and some recommendations and conclusions provided.

\section{MODEL AND DATA}

The measurement of the technique efficiencies was first proposed by Farrell (1957) and was later developed further by many other scholars. The methods of the measurement and calculation for technique efficiencies include mainly non-parametric methods based on data envelopment analysis (DEA) and parametric methods based on stochastic frontier analysis (SFA). There is no need for DEA to assume a specific form of production function compared to SFA, whereas linear programming can be used to measure technique efficiency. The main disadvantage of the DEA method is that it is difficult to account for the impacts of random factors on outputs which may affect the evaluation accuracy. Therefore, this study uses SFA to evaluate technique efficiencies and their influencing fiscal factors at a provincial level.

The SFA model was first developed by Meeusen and Broeck (1977), Aigner et al. (1977) and Battese and Corra (1977) on the basis of the traditional production function by introducing a random disturbance term. Its basic model can be expressed as:

$$
Y=f(X ; \beta) \cdot \exp (V-U)
$$

where $\mathrm{Y}$ represents output, $\mathrm{X}$ is a group of input vector, $\beta$ is a group of parameter vector to be estimated; $\exp (\mathrm{V}-\mathrm{U})$ is an error item, where $\mathrm{V}$ represents the deviation of the output boundary caused by the random errors, often assumed $V \square i i d N\left(0, \sigma_{V}^{2}\right)$; $\mathrm{U}$ is independent from $\mathrm{V}$ means the deviation of production and boundary caused by technique are valid and $U \square i i d\left|N\left(0, \sigma_{U}^{2}\right)\right|$ 。 The state of the individual technique efficiency can be represented by $\mathrm{TE}=\exp (-\mathrm{U})$.

This study is based on the SFA model formed by Battese and Coelli (1995) and uses the logarithmic C-D production function and panel data of China's provinces to evaluate the level of technique efficiencies $\left(\mathrm{M}_{\mathrm{it}}\right)$ and their influencing fiscal factors. The detailed form of the model constructed is shown below:

$$
\begin{aligned}
& \ln Y_{i t}=\beta_{0}+\beta_{1} \ln L_{i t}+\beta_{2} \ln K_{i t}+\left(V_{i t}-U_{i t}\right) \\
& M_{i t}=\delta_{0}+\delta_{1} E H_{i t}+\delta_{2} I C_{i t}+\delta_{3} D S_{i t}+\delta_{4} R D_{i t}+\varepsilon_{i t}
\end{aligned}
$$


Jia et al., Technique efficiency and financial crises in China

$$
\begin{aligned}
& T E_{i t}=\exp \left(-U_{i t}\right) \\
& \gamma=\frac{\sigma_{U}^{2}}{\sigma_{U}^{2}+\sigma_{V}^{2}}
\end{aligned}
$$

where, $\mathrm{Y}_{i t}, \mathrm{~L}_{i t}$ and $\mathrm{K}_{i t}$ represent respectively GDP, labour force and capital stock of the $i$ th province in year $t, \beta_{0}$ is a constant, $\beta_{1}$ and $\beta_{2}$ are parameters to be estimated representing respectively the output elasticity of labour force and capital; $V_{i t} \square i i d N\left(0, \sigma_{V}^{2}\right)$ are independent from $\mathrm{U}_{i t}, \mathrm{U}_{i t}$ are subject to being half normal distribution $N\left(M_{i t}, \sigma_{U}^{2}\right)$. The variables $\mathrm{EH}_{i t}, \mathrm{IC}_{i t}, \mathrm{DS}_{i t}$ and $\mathrm{RD}_{i t}$ represent respectively the values of expenditures on education and health, defence and security, public goods and R\&D which have been taken after the natural logarithm in the $i$ th province in year $t$. We assume the government's expenditure on education health, defence and security, public goods and R\&D as a group of influencing factors. Through evaluating the $\delta_{i}$ parameters, we can obtain the relative level of influence on technique efficiency for each expenditure. $\mathrm{TE}_{i t}$ are the technique efficiencies in the $i$ th province in year $t . \gamma \in[0,1]$ is also a parameter to be estimated, which reflects the ratio of variation of errors from $U$, where it is necessary to test $\gamma$. If $\gamma=0$ is accepted, $U_{i t}$ can be removed from the model and the parameter will not need to adopt the stochastic frontier model and can use directly the least squares method.

Statistical 1995-2009 data for 30 Chinese provinces are used to empirically evaluate the technique efficiencies and their influencing factors. The current existing statistical database does not cover capital stock data for individual provinces, but some evaluation exists. For example, Zhang et al. (2004) developed a good method whose basic formula has been adopted in this study as shown below:

$$
K_{i t}=K_{i t-1} \cdot\left(1-\eta_{i t}\right)+I_{i t}
$$

where $\mathrm{K}_{\mathrm{it}}, \mathrm{I}_{\mathrm{it}}$ are respectively the capital stock in the ith province in year $\mathrm{t}$ and gross fixed capital formation, $\eta_{\text {it }}$ is capital depreciation rate $(9.6 \%$ obtained in this study). Using equation 6 , the capital stock of each province during the 1995-2009 period can be calculated.

Furthermore, provincial expenditure on defence and security is the total of the expenditure on defence and armed police force; expenditure on public goods is the total of expenditure on provincial basic construction (mainly infrastructure); R\&D expenditure is the total expenditure on science and technology (S\&T) and research and development (R\&D). The data was obtained from the 1996-2010 China statistical yearbooks.

\section{EVALUATION}

Using Frontier 4.1 software, we evaluated the SFA model constructed in section 2 by the Maximum Likelihood

\begin{tabular}{|c|c|c|c|c|}
\hline \multicolumn{2}{|r|}{ Variables } & Parameters & Coefficient & Standard Deviation \\
\hline \multirow{3}{*}{$\begin{array}{l}\text { Production } \\
\text { Frontier } \\
\text { Function } \\
\end{array}$} & Constant & $\beta_{0}$ & $-1.276^{* * *}$ & 0.135 \\
\hline & Labour force & $\beta_{1}$ & $0.253^{* * *}$ & 0.016 \\
\hline & Capital & $\beta_{2}$ & $0.870^{* * *}$ & 0.016 \\
\hline \multirow{4}{*}{$\begin{array}{l}\text { Technical } \\
\text { Inefficiency } \\
\text { Function }\end{array}$} & education and health expenditures & $\delta_{1}$ & $-0.293^{* * *}$ & 0.037 \\
\hline & \begin{tabular}{|l|} 
Public goods expenditures \\
\end{tabular} & $\delta_{2}$ & $-0.121^{* * *}$ & 0.045 \\
\hline & Defence and safety expenditures & $\delta_{3}$ & -0.007 & 0.010 \\
\hline & R\&D expenditures & $\delta_{4}$ & $-0.209^{* * *}$ & 0.028 \\
\hline \multicolumn{2}{|r|}{$\sigma^{2}$} & \multicolumn{3}{|c|}{$0.051^{* * *}(0.005)$} \\
\hline \multicolumn{2}{|r|}{$\gamma$} & \multicolumn{3}{|c|}{$0.974^{* * *}(0.059)$} \\
\hline & One-sided likelihood ratio test & \multicolumn{3}{|c|}{82.868} \\
\hline \multicolumn{2}{|r|}{ Efficiency Average } & \multicolumn{3}{|c|}{0.8682} \\
\hline
\end{tabular}
method. Table 1 shows the parameter estimation and hypothesis test results.

Table 1. SFA model parameter estimation values and fiscal expenditures' impact on technique efficiencies

Note: ${ }^{* * *}$ indicates the significance at $1 \%$ level, ${ }^{* *}$ indicates the significance at $5 \%$ level, ${ }^{*}$ indicates the significance at $10 \%$ level. LR is likelihood ratio test statistics and it is consistent with the Mixed Chi-square LR Distribution. The negative sign in the inefficiency function indicates the positive impact of variables on technique efficiencies, and vice versa.

The results from the SFA model indicate that the estimated coefficients of the explanatory variables are consistent with the theoretical expectations and are statistically significant. According to table $1, \gamma=0.974$ and passed the significant test at the $1 \%$ level, which demonstrates that $97.4 \%$ of the production function error is from the efficiency factors of the provinces. This shows that non-efficiency factors can explain the significance of the total error of the model as well as the rationality and reliability of SFA. The likelihood ratio tests reject the null hypothesis ${ }^{1}$ of non-existing technique inefficiencies.

\footnotetext{
${ }^{1}$ In this model, $\mathrm{LR}=82.868$, which is obviously larger than the mixed chi-square distribution threshold of $1 \%$
} 
The output elastic coefficient of labour force and capital are respectively 0.253 and 0.870 , and they both passed the $1 \%$ significance test, which means the elasticity of capital is much higher than that of the labour force. Capital plays a leading role in the current economic growth in China. The output elasticity of China's labour force is relatively low, therefore China's economy can be accelerated through improving labour quality and increasing the labour's output elasticity. The tests of returns to scale indicate that the summary of elasticity of capital and labour force is greater than 1, which means that the increase in inputs of capital and labour can still promote China's provincial economy without considering progress in technique and human capital externalities. Similar research outcomes have been suggested by He (2004) and Yuan et al. (2005).

Among the factors influencing technique efficiency, the coefficients of expenditures on education and health, public goods and R\&D are respectively $-0.293,-0.121$ and -0.209 , all of which passed the $1 \%$ significance test. This indicates that when government expenditures on education and health, public goods and R\&D increase by $1 \%$, this will cause an increase of respectively $0.293 \%, 0.121 \%$ and $0.209 \%$ in provincial technique efficiencies. This means that government expenditure on education and health have enhanced the technique efficiencies through improving labour productivity and effective labour supply. It also suggests that expenditures on public goods and R\&D play a significant role in enhancing technique efficiencies through improving capital productivity and effective capital supply. The evaluation results show that the coefficient of government expenditures on defence and public order is -0.007 , which however didn't pass the significance test. Although social and political stability may influence capital productivity through influencing the efficiency of resource configuration, the results of this study suggest this is insignificant.

Table 2 ranks the 2009 technique efficiencies of China's eastern, central and western regions. The technique efficiencies in the eastern region are higher than those for the central and western regions with the lowest technique efficiency located in the west. Eight of the top 10 provinces are located in the eastern region due to the sound economic base, human capital, capital environment and the high level of opening up of the eastern coastal region (Hu et al., 2010). Among the 11 provinces of the western region, 6 are in the bottom 10 of the ranking. This indicates that the poorly developed western region has low technique efficiencies, in many ways due to underinvestment by the Chinese central government in these provinces and only relatively recent strategies to "Open Up the West" (Goodman, 2004). Improving the technique efficiencies in the western region should be a practical option to accelerate its economic development.

Table 2. Ranking of China's technique efficiencies, 2009

\begin{tabular}{|c|c|c|c|c|c|c|c|c|}
\hline \multicolumn{3}{|c|}{ Eastern Region } & \multicolumn{3}{|c|}{ Central Region } & \multicolumn{3}{|c|}{ Western Region } \\
\hline Provinces & $\begin{array}{l}\text { Technique } \\
\text { Efficiency }\end{array}$ & Rank & Provinces & $\begin{array}{l}\text { Technique } \\
\text { Efficiency }\end{array}$ & Rank & Provinces & $\begin{array}{l}\text { Technique } \\
\text { Efficiency }\end{array}$ & Rank \\
\hline Beijing & 0.9442 & 4 & Shanxi & 0.8600 & 21 & Inner Mongolia & 0.9157 & 8 \\
\hline Tianjin & 0.9611 & 1 & Jilin & 0.8809 & 16 & Guangxi & 0.8519 & 22 \\
\hline Hebei & 0.8240 & 26 & Heilongjiang & 0.8986 & 10 & Sichuan & 0.8469 & 24 \\
\hline Liaoning & 0.9264 & 6 & Anhui & 0.8232 & 27 & Guizhou & 0.8057 & 30 \\
\hline Shanghai & 0.9605 & 2 & Jiangxi & 0.8225 & 28 & Yunnan & 0.8132 & 29 \\
\hline Jiangsu & 0.9323 & 5 & Henan & 0.8764 & 17 & Tibet & 0.8459 & 25 \\
\hline Zhejiang & 0.9231 & 7 & Hubei & 0.8752 & 18 & Shaanxi & 0.8629 & 20 \\
\hline Fujian & 0.9152 & 9 & Hunan & 0.8930 & 12 & Gansu & 0.8478 & 23 \\
\hline Shandong & 0.8873 & 14 & & & & Ningxia & 0.8984 & 11 \\
\hline Guangdong & 0.9586 & 3 & & & & Qinghai & 0.8702 & 19 \\
\hline Hainan & 0.8906 & 13 & & & & Xinjiang & 0.8859 & 15 \\
\hline Average & 0.9203 & & Average & 0.8662 & & Average & 0.8586 & \\
\hline \multicolumn{4}{|c|}{ National Average } & \multicolumn{5}{|c|}{0.8833} \\
\hline
\end{tabular}

Figure 1 shows the 19952009 trend in technique efficiencies of China's regions. There was an overall increase in technique efficiencies in all regions with the average provincial technique efficiency rising from 0.7675 in 1995 to 0.8833 in 2009 with an increase of $15 \%$. However, the distribution of China's technique efficiencies demonstrates a serious regional imbalance with the values for the eastern region being relatively higher than those for the central and western regions. The technique efficiencies of each year in the western region are

and is also larger than the threshold suggested by Kodde and Palm (1986), therefore the null hypothesis of non-existing technical void effect can be rejected. 
lower than those for the eastern and central regions which had greater inter-annual fluctuations. Since 1995, the average technique efficiencies in the eastern, middle and western regions have increased respectively $13.1 \%$, $16.1 \%$ and $16.5 \%$, which shows a trend towards convergence in regional imbalance.

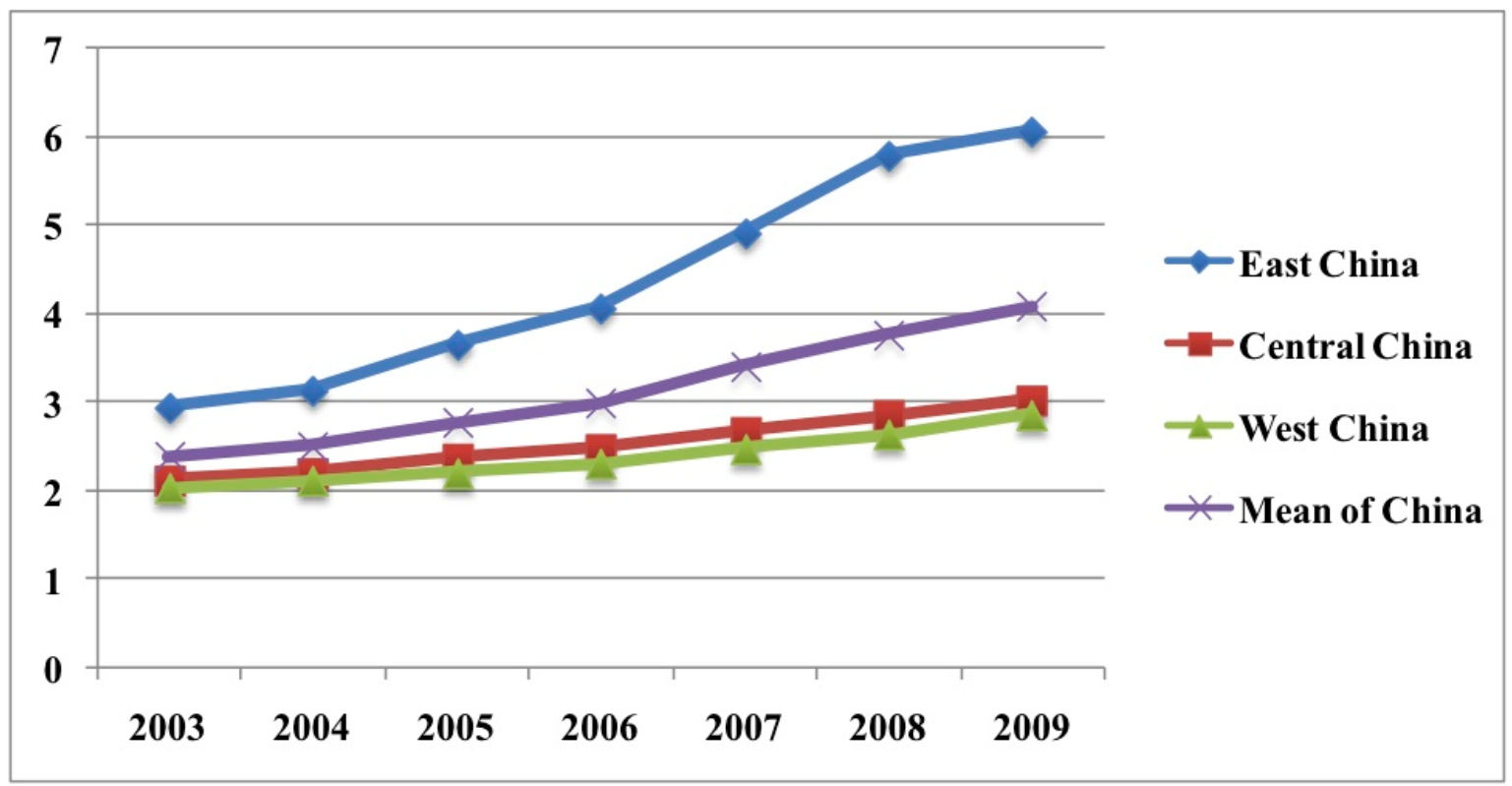

Figure 1. Changing trends of technique efficiencies in Chinese regions, 1995-2009

\section{CHINA'S PROVINCIAL TECHNIQUE EFFICIENCY AND FINANCIAL CRISES}

China's economy was on a trajectory of recovery (with an average GDP growth rate of 10\% for 1998-2008) from the 1997 Asian financial crisis, when it was hit again by the 2008 global financial crisis. The GDP growth rate dropped significantly from 14.2\% in 2007 to $9.6 \%$ in 2008 (NBSC, 2011). The impact of both financial crises on China have drawn a lot of attention (e.g. Kemenade, 1999; Liu, 2009) but the main focus has been on the macroeconomic level while we examine this in the context of technique efficiency.

Although there was an overall increase in the provincial technique efficiencies, some volatility was observed in 1997, 2008 and 2009 (see Figure 1), which shows that both financial crises have had an impact on the provincial technique efficiencies with a greater volatility during the Asian financial crisis. China's average provincial technique efficiency decreased from 0.8499 to 0.8271 (or 2.69\%) between 1996 and 1997. In addition there was a decrease of respectively $2.08 \%, 1.38 \%$ and $4.29 \%$ in the eastern, central and western regions and there were varying degrees of decline in the technique efficiencies in 29 provinces. In 2008 the global financial crisis continued to send shockwaves with the growth rate of the provincial technique efficiencies lower than in 2007 for 17 provinces; in particular, the average growth rate in the central region decreased by $0.05 \%$. In 2009, the global financial crisis had additional impacts on the technique efficiencies which caused China's average provincial technique efficiency to decrease by $1.06 \%$ of the 2008 rate.

Compared to the Asian financial crisis, the impact of the global financial crisis was lower but lasted longer. It might be the case that China's economic strength was smaller when the Asian financial crisis outbreak started. For instance, the GDP in 1997 reached 7897.3 billion yuan $\left(7^{\text {th }}\right.$ in the world) but there was also a financial deficit which accounted for $0.74 \%$ of GDP due to China's relatively weak economic system. Therefore there was greater volatility in the technique efficiencies in the wave of the Asian financial crisis. However, there has been a great improvement in China's recent economic strength, particularly with a five consecutive years of economic growth rate of over 10\% from 2003 to 2007 when its GDP reached 24661.9 billion yuan, making China the $3^{\text {rd }}$ largest economy in the word. In 2007, China's financial income reached 5.1 trillion yuan and achieved fiscal surplus of $0.28 \%$ of GDP. This proved that China's risk-resistance ability was stronger than ever. However due to the complicated domestic and international situations that China had to face, such as the strong earthquake in Wenchuan of Sichuan province and other serious natural disasters, the global financial crisis of epic proportions affected China's technique efficiencies for a longer period. 
Jia et al., Technique efficiency and financial crises in China

\section{CONCLUSION AND RECOMMENDATIONS}

Based on the SFA, this study evaluated the 1996-2009 trends of China's provincial technique efficiencies, including the influence of government expenditure on education and health, public goods, defence and security and R\&D. It also examined the impacts of the 1997 Asian financial crisis and the 2008 global financial crisis on the technique efficiencies. Below are some conclusion and recommendations:

- The elasticity of China's labor productivity outputs is relatively low due to the poor quality of the labour force - an important factor which constrains China's economic development. Promoting China's labour force transformation and training and improving the quality of the labour force are the two important considerations in formulating future economic development policies in China.

- Expenditures on education, health, public goods and R\&D can enhance significantly the technique efficiencies. Optimising the structure of the expenditure and improving its efficiencies are the main tasks for increasing the provincial technique efficiencies in China.

- The technique efficiencies of the eastern part of China are much higher than those of the middle and western parts. Improving the technique efficiencies of the middle and western parts, including providing more financial assistance from the central government, becomes very important for accelerating their economic development and changing the backward status of these regions.

- Both financial crises have impacted the technique efficiencies of China's provinces, with bigger shockwaves sent by the Asian financial crisis and a longer period of impact for the global financial crisis.

\section{ACKNOWLEDGEMENT}

The last two authors want to acknowledge the financial help of the Australian Research Council (ARC) which made it possible for them to participate in this research.

\section{REFERENCES}

Aigner D., C.A. Lovell and P. Schmidt (1977). Formulation and estimation of stochastic frontier production function models. Journal of Econometrics, 6(1), 21-37.

Battese G.E. and G.S. Corra (1977). Estimation of a production frontier model: With application to the pastoral zone of eastern Australia. Australian Journal of Agricultural Economics, 21(3), 169-179.

Battese G.E. and T.J. Coelli (1995). A model for technical inefficiency effects in a stochastic frontier production function for panel data. Empirical Economics, 20(2), 325-332.

Fan A. and L. Wang (2009). Regional technical efficiency differences and growth convergenc of China's provinces. Economist, 23(4), 83-89.

Farrell M. J. (1957). The measurement of production efficiency. Journal of Royal Statistical Society, 120(3), 253-281.

Fu X. and L. Wu (2006). Technical efficiency, capital deepening and regional disparity. Economic Research Journal, 41(12), 52-61.

Goodman, D.S.G. (Ed.) (2004). China's Campaign to "Open Up the West": National, Provincial-level and Local Perspectives. Cambridge University Press, Cambridge.

$\mathrm{Hu}$ X., W. Zhang and L. Yang (2010). Institutional environment, technical efficiency and regional economic growth differences. Journal of Public Management, 7(2), 79-88.

Kemenade W. (1999). Besieged: China, Hong Kong, and Taiwan in the Asian financial crisis. The Washington Quarterly, 22(3), 165-179.

Kodde D.A. and F. C. Palm (1986). Wald criteria for jointly testing equality and inequality restrictions. Econometrica, 54(5), 1243-1248.

Lau K.T. and J.C. Brada (1990). Technological progress and technical efficiency in Chinese industrial growth: a frontier production function approach. China Economic Review, 1(2), 113-124.

Lichtenberg F.R. (1992). Industrial de-diversification and its consequences for productivity. Journal of Economic Behavior \& Organization, 18(3), 427-438.

Liu L. (2009). Impact of the global financial crisis on China: Empirical evidence and policy implications. China \& World Economy, 17(6), 1-23.

Lucas R. (1988). On the mechanics of economic development. Journal of Monetary Economics, 22(1), 3-42.

Meeusen W. and J. Broeck (1977). Efficiency estimation from Cobb-Douglas production functions with composed error. International Economic Review, 18(2), 435-444.

National Bureau of Statistics of China (NBSC) (2011). China Economic and Social Development Statistics Report. http://www.stats.gov.cn/tjgb/ndtjgb/qgndtjgb/t20110228_402705692.htm (accessed April 7, 2011) 
Uzawa H. (1965). Optimum technical change in an aggregative model of economic growth. International Economic Review, 6(1), 18-31.

Wang Z., L. Gong and Y. Chen (2006). China's regional differences in technical efficiency and the decomposition of total factor productivity growth (1978-2003). Social Sciences in China, 25(2), 55-66.

Wu Y. (1995). Productivity growth, technological progress, and technical efficiency change in China: a three-sector analysis. Journal of Comparative Economics, 21(2), 207-229.

Yuan P., X. Chen and R. Hu (2005). The empirical research on the effect of international trade to technical efficiency. Forecasting, 24(6), 52-55.

Zhang J., G. Wu and J. Zhang (2004). The estimation of China's provincial capital stock: 1952-2000. Economic Research Journal, 39(10), 35-44. 